\title{
Outsourcing, Information Leakage and Consulting Firms ${ }^{1}$
}

\author{
Mariagiovanna Baccara ${ }^{2}$
}

First version: Spring 2002, This version: November 2005

\footnotetext{
${ }^{1}$ I thank Patrick Bolton and Wolfgang Pesendorfer for advising me on this paper. I also thank Jennifer Reinganum, two anonymous referees, Jim Anton, Heski Bar-Isaac, Sandro Brusco, Luis Cabral, Alessandro Lizzeri, Ronny Razin and Marciano Siniscalchi for very helpful conversations, and the participants of seminars and presentations at University of Southampton, Fuqua School of Business (Duke), the 2003 SED meetings (Paris), the Tow Conference of Industrial Organization (University of Iowa), Stern School of Business (NYU) and Marshall School of Business (USC).

${ }^{2}$ Department of Economics, Stern School of Business, New York University (44 West Fourth Street, New York, NY 10012), Email: mbaccara@stern.nyu.edu
} 


\begin{abstract}
This paper offers a general equilibrium model to analyze the problem of R\&D investment of firms that also face the decision between outsourcing and in-house production in the presence of $\mathrm{R} \& \mathrm{D}$ information leakage. A contractor hired by a firm learns the firm's technology and can diffuse the information to other firms, either by selling it or by "spilling" it involuntarily. I find that information leakage concerns tend to concentrate the outsourcing market with respect to a situation in which information leakage is not present. In particular, despite the fact that the original outsourcing market is perfectly competitive, I find that when a market for information arises in equilibrium, such a market is always monopolistic. I show that a market for information arises when contractors have a positive but low degree of control on the information they hold. If contractors do not have any control on the information they hold, the market splits into a positive measure of technologically advanced firms that never outsource and a positive measure of low-tech firms that always outsource. If contractors have full information control, all firms invest in technology and outsource, and a market for information never arises. The structure of the equilibria of the model captures several features observable in the management consulting industry.
\end{abstract}




\section{Introduction}

This is an era in which R\&D development has emerged as one of the firm's most valuable assets. As a consequence, protecting the secrecy of R\&D information is a crucial concern in industrial organization. ${ }^{1}$ While close monitoring and career concerns can help to mitigate the leakage of information caused by its own employees, a firm is particularly vulnerable to this problem when it interacts with the external world, and in particular when outsiders collaborate in the production process. $^{2}$

On the other hand, a vast literature documents how increasing specialization and economies of scale induce firms to rely on outsourcing for an expanding number of productive activities, including even temporary workers. ${ }^{3}$ When a firm hires an external contractor, information sharing is often a necessity, and, even when it is not, the close relationship with a contractor can result in an involuntary information leakage. Thus, external contractors may end up aggregating information coming from the pool of their clients, and as a result other firms may have an incentive to hire the same contractors to have access to that same information.

This paper aims to explore the role of contractors as information intermediaries and the trade-off between hiring efficient contractors and protecting R\&D information from expropriation. In particular, I study the implications of this trade-off on the R\&D investment, the information diffusion in an industry and on the size and structure of the outsourcing market. Since the value of the information acquired by contractors depends on the strategic choices of all their clients, this paper tackles these questions using a general equilibrium approach. This allows to derive the market value of information and to study the characteristics of the downstream market

\footnotetext{
${ }^{1}$ See Levin et al. (1987) for a survey on how firmstypically rely on secrecy rather than patents to appropriate the returns of $\mathrm{R} \& \mathrm{D}$.

${ }^{2}$ See Rajan and Zingales (2001), Zabojnik (2002), Baccara and Razin (2002) and Baccara and Bar-Isaac (2005) for analyses of situations in which a firm's employees (or former employees) can leak crucial information outside the firm.

${ }^{3}$ Among others, see Feenstra (1998), Tempest (1996), Helper (1991), Abraham and Taylor (1996), Grossman and Helpman (2000, 2001), World Trade Organization Report (1998). For temporary help supply (THS), see Estevao and Lach (1999).
} 
for information that can endogenously arise in equilibrium.

I develop a model in which firms invest in cost-cutting technology and operate in a monopolistic competitive market. The production of each firm's good includes two stages: the first stage of production consists of a fixed task. Such task can be performed either in-house or by a specialized contractor, and it is the same for all firms. The "task" represents any stage of production that can in principle be outsourced, including legal advice, IT, banking, accounting, inputs manufacturing, and so on. The contractor is selected among the ones that populate a perfectly competitive outsourcing market. If a firm hires a contractor, the contractor learns the technology developed by the firm. The second stage of production can be only completed in-house, and its (variable) cost is determined by the technology available to each firm.

Once a contractor learns a technology, and before the second stage of production takes place, the technology may "leak" to some competing firms. The information leakage can occur in two fundamental ways: first, a contractor may not have perfect control of the information that he learns. This lack of control determines an unintentional spill of information to a fixed measure of other firms. Second, each contractor can post a price for the information he knows and sell it to other firms.

The (exogenous) magnitude of the spill measures the ability of the contractors to protect and market the information they have. Sometimes, contractors may not have the expertise to understand and sell information on the market. Other times, geographical concentration (e.g., firms in Silicon Valley), or high employee turnover (e.g., management consulting firms) could cause a contractor not to be able to fully control the information flows coming from his firm. ${ }^{4}$ A more sophisticated contractor may take measures to protect the value of the information and limit the spill to some degree. A contractor has perfect control of the information when he does not generate any involuntary spill. In this model, the magnitude of the

\footnotetext{
${ }^{4}$ The presence of the "spill" is consistent with the wisdom that the resources present in professional firms are not fully appropriable. E.g., consulting firms have very high employee turnover as employees often leave the firm to work with a current or a potential client [Bhide (1996)].
} 
information spill affects the demand for information and the size of the market that the contractors face as information sellers.

I study the equilibria of this model as the magnitude of the information spill varies. First, if a contractor has some degree of control over the information, there always exists a unique equilibrium in which a market for information arises. Quite strikingly, despite the fact that the outsourcing market is perfectly competitive, the market for information in equilibrium is always monopolistic. The intuition of this result is very general and robust. Consider the problem of a firm that invested in R\&D. This firm also has to decide whether to hire a contractor and, in case it does, it has to select a contractor from the ones that populate the outsourcing market. In making these decisions, the firm has to consider the impact of its choice on the market for information that will arise downstream. In particular, the firm always has an incentive to distort such a market by keeping it as concentrated as possible. This is because when the degree of competition in the market for information increases, the price for information decreases. Thus, more firms buy information on the market, and the information leakage increases. On the other hand, a more concentrated market for information guarantees a higher price for information and more limited leakage to the rest of the market. Then, information leakage concerns have the tendency to concentrate the outsourcing market with respect to situations and industries in which information leakage is not present. ${ }^{5}$

When contractors face the financial constraint of posting a non-negative price for the task, the ex-ante competition to become the information monopolist does not dissipate the surplus from the market for information. Thus, the contractor who becomes the information monopolist appropriates all the surplus of the market for information.

If the contractors have full control over the information, I show that there cannot be a market for information in equilibrium. In this case, firms know that if they

\footnotetext{
${ }^{5}$ In this model, this intuition translates in the stark equilibrium outcome in which the market for information is always a monopoly. For the generality of this intuition and the robustness of the monopoly result to several modifications of the model, see the Web Appendix.
} 
do not invest in technology, a monopolistic contractor will be their only source to learn cost-cutting technology in the future. If contractors cannot ex-ante commit to a price for information, the information monopolist always prices it to extract all the information surplus. If this is the case, firms always prefer to invest in the technology themselves rather than wait to be charged a high price by the information monopolist. As a result, with full information control, there is only one equilibrium in which all firms invest in technology, outsource, and there is no market for information. ${ }^{6}$

Finally, I analyze the case in which contractors have no control over the information they learn. In this case a market for information cannot arise, and I identify necessary and sufficient conditions for the existence of a unique equilibrium in which the market splits into a positive measure of firms outsourcing and not investing in technology and a positive measure of firms that have a high technology level but perform the task in-house. ${ }^{7}$

I compare the equilibrium investment and the diffusion of the technology under different degrees of contractors' information control. I show that the technology level reached in the market decreases as the degree of control over the information of the contractors increases. However, the measure of firms that adopt the technology increases with the degree of information control. From that, I derive some welfare implications of the model.

\footnotetext{
${ }^{6}$ This suggests that, for instance, consulting firms prefer to stay away from a situation in which they have full control over the information they hold and no commitment power over the price for it. This is consistent with well-established consulting firms' practices of committing to a high employees' turnover and, until recently, updating the fees they charge their clients once a year on a general (and not per-project) basis. Also, this is consistent with the high labor mobility patterns observed in Silicon Valley (see also Lewis and Yao (2001)).

${ }^{7}$ Such equilibrium is consistent with the hardware market of the 80's and early 90's, when Apple Computer famously avoided outsourcing and carefully protected its R\&D investments, while PC hardware producers adopted arguably lower technology standards and a very intensive outsourcing activity.
} 


\subsection{An Example: Management Consulting Firms}

While the question addressed in this paper applies to a wide range of outsourcing activities, it can be related in a interesting way to the case of the Management Consulting industry.

In the model, contractors learn $\mathrm{R} \& \mathrm{D}$ information as a byproduct of the main activity (or "task") they are hired for. If a contractor understands the market value of the information, and has the capabilities to market it, he could try to sell it to other firms.

Historically, several very successful management consulting firms originated as a small consulting practice within a firm specializing in professional services such as accounting, auditing, tax filing or engineering. ${ }^{8}$ This suggests that the transition from professional service to consulting may have happened to capitalize on the expertise these professionals developed working at close contact with their clients.

Even the current management consulting industry fits the model quite well. It is very difficult to define the products that are traded in this industry. These products are sometimes identified with organizational ideas, other times with the necessity to validate some unpopular decisions such as personnel reduction, and so on. ${ }^{9}$ However, products that management consultants explicitly market and sell are the so-called "best practices". "Best practices" are benchmarks that are usually formulated by aggregating the information that consultants gather from the pool of

\footnotetext{
${ }^{8}$ McKinsey \& Co. originated from "James O. McKinsey \& Co.", a firm specializing in accounting and management engineering, and its successive merger with "Scovell, Wellington \& Co.", another accounting firm. The first years of the partnership were characterized by a heated debate on the decision of keeping the accounting and the consulting practices separate or under the same roof [see Bhide (1996)]. Other major accountancy offered consultancy type advice to their clients at a small scale, and from the 1980s onward they expanded these kind of services [see Kipping and Armbruster (2004)]. In particular, Arthur Andersen was best known as an audit and accounting firm, but its business consulting practice became its most successful division, growing at around $25 \%$ annually in the late '90s. Finally, in Europe the clients of notaries public often refer to them for business advice too.

${ }^{9}$ See McKenna (2001) and Bhide (1996) for some informal theories on the role and added value of management consultants.
} 
their clients on a given common issue. ${ }^{10}$ As McKenna (2001) puts it: "Management consultants have primarily functioned as disseminators of organizational ideas". In the words of sociologists DiMaggio and Powell (1983) "Large organizations choose from a relatively small set of major consulting firms which, like John Appleseeds, spread a few organizational models throughout the land". ${ }^{11}$

Suppose that a firm with some good technology related to a given function decides to hire a management consultant for some reason (e.g., to acquire a "best practice" related to some other function, a better organization, to validate some personnel reduction, etc.). Once the management consultants are hired, they typically send a team to work for a period of time that ranges from some months to years on location at the client's headquarters. During their stay, this team has access to a large portion of the firm's private information. So, it is natural that the firm may be worried that the technology they hold becomes part of some other "best practice" sold to some competitor in the future. ${ }^{12}$

Because of its high labor turnover, a management consulting company typically does not have a perfect control of the information it aggregates. ${ }^{13}$ Thus, the case of the model this industry seems to match is the case of imperfect control of information. This is the case under which a market for information arises in equilibrium and the consultants appropriate the surplus of this market in the long run.

Finally, the results of the paper predict that a monopoly is the only possible equilibrium outcome when a market for information arises. Such result (or, more generally, the intuition that information leakage concerns tend to concentrate the consulting market) is consistent with the observation that among many accounting or auditing firms, only a few made a transition to become successful consulting firms.

\footnotetext{
${ }^{10}$ Before being aggregated, this information is typically "sanitized" that is, the sources of every piece of information are purged.

${ }^{11}$ For an extensive discussion and literature review on management consultants as knowledge intermediaries, see Kipping and Armbruster (2004).

${ }^{12}$ A common explanation comes from the consultants' reputation concerns. However, the "best practice" paradigm seems to be well understood and accepted, so the puzzle does not seem to be completely explained by reputation arguments.

${ }^{13}$ Again, see Bhide (1996) for a discussion of high labor turnover in management.
} 
Moreover, the management consulting industry is characterized by high market concentration and high growth of a few market leaders. In particular, in 2001, McKinsey had $40.6 \%$ of the market share and in the late 1990s it experienced a growth of 20\% annually. Moreover, McKinsey and its largest competitor, Booz, Allen \& Hamilton, together held almost $60 \%$ of the market in $2001 .^{14}$

\subsection{Related literature}

After Coase (1937) originally identified the "make-or-buy" decisions as the element that defines the boundaries of a firm, and Williamson $(1975,1985)$ more recently re-explored Coase's fundamental intuition, a vast literature started to analyze such decisions both in individual and in general industry equilibrium settings. Very influential work on this issue has been carried out by Klein et al. (1978), Grossman and Hart (1986), and Hart and Moore (1990), and it has focused mainly on what is known as the "hold-up problem", arising from relation-specific investments and incomplete contracts. However, as Holmstorm and Roberts (1998) have pointed out in a recent article, explaining the boundaries of the firm only in terms of the holdup problem and asset-specificity seems a too narrow view for a very general issue. The aim of this paper is to introduce a new possible perspective for "make-or-buy" decision, which is based on informational concerns.

The approach of this paper is close to the one in two papers by Grossman and Helpman (2002a and 2002b). This is because, rather than taking a decision theoretic approach in which the industry environment is given, I consider a general equilibrium model that allows to study the interdependence among firms and sectors. Between those two papers, Grossman and Helpman (2002a) is the closest to this one since it focuses on firms'make-or-buy decision. ${ }^{15}$ However, in that paper the fundamental trade-off the firms face when they make such a decision is substantially different from the one I consider here. Namely, rather than facing an informational concern that

\footnotetext{
${ }^{14}$ See Business Week, 7/8/2002.

${ }^{15}$ Grossman and Helpman (2002b) focuses instead on activities that need to be outsouced and analyzes what determines the location of the sub-contracted activity.
} 
may erode the return of their investment in $R \& D$, the firms face the choice of high governance costs from being vertically integrated, or search costs to find a more specialized and lower cost partner. In addition, because of incomplete contracts and the specialized investment required, specialized partners face a potential holdup problem. Similarly to this paper, Grossman and Helpman (2002a) characterize the conditions under which we observe vertical integration, pervasive outsourcing, or coexistence of the two on a market. However, in this paper I also relate these events to information diffusion in the industry through the presence of the market for information.

Jovanovic and MacDonald (1994) analyze the evolution of a competitive industry in which firms reduce costs by innovating or imitating their rivals' technologies. In the steady state, they find that the diffusion of the technology from the investing firms to the imitating ones leads to a low level of investment. This effect is present in this paper as well. However, this paper focuses on endogenizing the mechanism through which the information spreads and on the role of contractors as information intermediaries. ${ }^{16}$

Another paper that analyzes the issue of property information flows in the firm-tofirm service markets is Demski et al. (1999). However, their focus is on the internal organization of the service-providing firm, and the problem of designing incentives to discourage employees from leaking information. In this paper, I abstract from the contractors' internal organization, I explicitly consider the possibility of a market for information arising in equilibrium and I study its properties and its consequences on investment in technology. ${ }^{17}$

There is a link between Proposition 7 and the literature on labor mobility and IP in Silicon Valley. In particular, Proposition 7 implies that if a contractor can choose between perfect control over the information he/she stores and a positive degree of

\footnotetext{
${ }^{16}$ See also Ceccagnoli (2000) for a model in which the equilibrium cost-cutting investment is affected by spill-overs to competitors.

${ }^{17}$ This paper is also related to the literature on the value and market for information. For very recent contributions to this literature and more references, I refer to Anton and Yao (2002(a) and (b)). See also Jansen (2005).
} 
spillover, the contractor will prefer to commit to a positive degree of spillover. In Silicon Valley, firms allow their employees to have frequent professional and social contacts with other firms' employees with which information is typically shared. For an interesting theoretical account for such phenomenon and an alternative view that focuses on incomplete contracts and the choice of the $R \& D$ environment as a tool in the bargaining between firms and employees, see Lewis and Yao (2001).

The result presented in Section 3 are related to the results on common agency of Bernheim and Whinston (1985). In Bernhein and Whinston's paper firms in competition may find it useful to delegate their marketing efforts to a common agent to solve their coordination problem and enjoy a collusive outcome. Although the idea of competitive firms using a common contractor is similar, in this model firms use of a common contractor in the production stage to guarantee a monopoly not in the product market, in which they still compete, but in a different, endogenously arising market, i.e. the market for information.

On the empirical side, the most recent contribution related to this paper is Azoulay (2004), which, in line with what this paper suggests, shows that pharmaceutical firms are more likely to outsource the coordination of data-intensive clinical trials, while knowledge-intensive trials are more likely to be assigned to internal teams. Moreover, Mayer (2000) carries out an empirical analysis on the use of subcontractors in the IT industry and finds that the presence of expropriable information lowers the likelihood of observing a subcontractor. ${ }^{18}$

The rest of the paper is organized as follows. The model is introduced in Section 2. In Section 3, I characterize the equilibria of the case in which contractors have either some or full degree of control over the information. The analysis of the case in which contractors have no control over the information is carried out in Section 4. Section 5 is devoted to some comparative statics and welfare implications, and Section 6 concludes the paper offering the discussion of some assumptions and some suggestions for further research. Selected proofs appear in the Appendix; for the

\footnotetext{
${ }^{18}$ See also Bartel, Lach and Sicherman (2005) on the link between IT outsourcing and the hightech revolution.
} 
remaining proofs, see the Web Appendix at www.rje.org.

\section{A model of outsourcing and information leak- age}

\subsection{Firms and consumers}

Consider a monopolistically competitive market populated by a fixed interval of firms $\mathcal{N}=[0, n]$. The preferences of the representative consumer are described by a Dixit-Stiglitz utility function

$$
u(y)=m+W \ln \left[\int_{0}^{n} y(i)^{\alpha} d i\right]^{1 / \alpha}
$$

where $y(i)$ is the consumption of the good produced by firm $i \in \mathcal{N}, m$ is the numeraire, $W>0$ and $\alpha \in(0,1)$. As it is well-known, utility maximization subject to the budget constraint $m+\int_{0}^{n} p(i) y(i) d i \leq E$, yields to the demand function for good $i$ given its price $p(i)$ is

$$
y(i)=M p(i)^{-\frac{1}{1-\alpha}}
$$

with $M \equiv \frac{W}{\int_{0}^{n} p(j)^{-\frac{\alpha}{1-\alpha}} d j}$.

Each firm $i \in \mathcal{N}$ can invest an amount $k(i) \in R_{+}$in developing cost-cutting technology. ${ }^{19}$ Such investment reduces the (constant) marginal cost of production of the firm according to the function $c(k)=(1+k)^{-\rho}$ with $\rho \in(0,1) .{ }^{20}$ As I describe

\footnotetext{
${ }^{19}$ I focus on cost-cutting R\&D rather than product development to abstract from reverse engineering or IPR issues (it is difficult for patent-holders to monitor infringements of their cost-cutting techniques). However, as long as reverse engeneering is not possible and IPR are absent, the alternative modelling choice would lead to similar results.

${ }^{20}$ Notice that I do not require all the firms to develop the same technology, but I assume that two technologies developed with the same investment $k$ cut the costs to the same level $c(k)$. Also, I focus on a particular functional form for $c(\cdot)$ for simplicity. None of the results of the paper crucially depend on the specific characteristics of this functional form.
} 
later, a firm can cut its marginal costs also by learning a technology developed by someone else.

To focus the analysis on the most interesting cases, I assume that the parameters of the model satisfy the following requirements: ${ }^{21}$

Assumption $1 \alpha$ and $\rho$ satisfy $\rho<\frac{1-\alpha}{\alpha}$.

Assumption 2 The parameters of the model satisfy $W \alpha \rho>n$.

Before carrying out any amount of production, each firm has to perform a fixed task. A task represents any function that can be outsourced. The (fixed) cost of the task, which I will denote by $\tau$, is either equal to $t>0$, if the task is performed in-house, or $\tau_{j}$ if it is outsourced from contractor $j$, where $\tau_{j}$ is the price posted by contractor $j$ (see below).

\subsection{Contractors}

The outsourcing market is populated by a finite set $\mathcal{M}$ of $m \geq 2$ identical contractors. Since contractors specialize in the task, they can perform it more efficiently than the firms. By simplicity, I assume that contractors have zero marginal cost when performing the task for one additional firm. ${ }^{22}$ Thus, the parameter $t$ measures the efficiency of the contractors in performing the task. Each contractor $j \in \mathcal{M}$ sets a price $\tau_{j} \in R$ to perform the task for a client. ${ }^{23}$

As long as firms do not outsource the task, the cost-cutting technology that they develop is known only within their boundaries. ${ }^{24}$ When a firm hires a contractor,

\footnotetext{
${ }^{21}$ Assumption 1 guarantees that the Second Order Conditions of the optimal investment problem are satisfied. Assumption 2 guarantees that, unless they anticipate learning some technology developed by competitors, firms always invest in equilibrium. To see this, the first order condition of the optimal investment problem is $\frac{W(1-\alpha)}{\int_{n}(1+k(j))^{\frac{\alpha \rho}{1-\alpha}} d j} \frac{\alpha \rho}{1-\alpha}\left(1+k^{*}\right)^{\frac{\alpha \rho-1+\alpha}{1-\alpha}}-1=0$. By symmetry, we get that $k^{*}>0$ if $W \alpha \rho>n$.

${ }^{22}$ Alternatively,one can assume that contractors have increasing returns of scale. This alternative assumption reinforces the main results presented in this paper.

${ }^{23}$ Notice that, even if Corollary 6 explores the case in which contractors face the borrowing constraint $\tau_{j} \geq 0$, such assumption is not made in any other part of the paper. Thus, any contractor $j$ is allowed to post any $\tau_{j} \in R$.

${ }^{24}$ Employees may be loyal for career concerns, because they are given the right incentives, or
} 
the contractor perfectly learns the cost-cutting technology developed by the client. ${ }^{25}$

As a contractor can be hired by many firms simultaneously, he may learn different pieces of information. For simplicity, I make the following assumptions regarding information aggregation: first, I assume that technology knowledge cannot be cumulated, in the sense that if a contractor learns two cost-cutting technologies $c_{1}$ and $c_{2}$ such that $c_{2}>c_{1} \geq 0$, the minimum level of costs he can reach with this knowledge is $c_{1} \cdot{ }^{26}$ Moreover, technologies are assumed to be perfectly divisible, in the sense that if a contractor knows how to reach the cost level $c$, he knows how to reach any level of costs $\widetilde{c} \in[c, 1]$.

As a contractor learns the technology adopted by his clients, there are two ways through which this information diffuses to the rest of the market. First, a contractor who knows some information can sell any portion of it to the firms. Let $\underline{c}_{j}$ be the be the best technology developed within the set of the clients of contractor $j$. Then, contractor $j$ knows how to cut the marginal cost of a firm up to $\underline{c}_{j}$. By the perfect divisibility assumption, contractor $j$ can sell information that allows a firm to cut costs to any level $c_{j} \in\left[\underline{c}_{j}, 1\right]$. Then, after performing the task for his clients, a contractor decides the quality $c_{j}$ and the price $\psi_{j}$ of the information he wants to sell.

Second, contractors may not have perfect control on the information they learn. This lack of control can be caused by several factors, as an imperfect understanding of the relevance of the technology, imperfect monitoring of the employees, employees' turnover, etc. For simplicity, I capture this loss of control by assuming that the best technology learned by contractors (i.e., the technology $\underline{c} \equiv \min _{j \in \mathcal{M}} \underline{c}_{j}$ ) spills to a because they are easily monitorable. See Baccara and Razin (2002 and 2003) and Rajan and Zingales (2001) for frameworks in which employees can expropriate the information developed within a firm.

${ }^{25}$ For a discussion of the implications of relaxing this assumption, see Section 6 .

${ }^{26}$ These assumption could be substituted with alternative ways to aggregate information, e.g. by assuming that innovations are complementary (that is, by knowing a technology $c_{1}$ and a worse technology $c_{2}>c_{1}$, the contractor knows how to cut costs up to some $\widetilde{c}<c_{1}$ ). The implications of this extension are briefly discussed in Footnote 34. 
fixed subset of measure $s$ of the firms that do not have learned any technology yet (i.e., they did not invest in technology nor have they bought any information from the contractors). ${ }^{27}$ The parameter $s$ measures the degree of control that contractors have on the information they hold. When $s=n$, contractors always generate a spill that can reach the entire market. I refer to this situation as a "perfect spill", and I analyze it separately in Section 3. When $s \in(0, n)$ contractors have some degree of information control, but they still generate a positive information spill. When $s=0$, there is no spill and contractors have full control over the information they hold. ${ }^{28}$ An important assumption of this model is the fact that firms do not participate directly to the market for information, i.e. they are not allowed to sell information to their competitors. This assumption and the consequences of relaxing it are discussed in detail in Section 6.

\subsection{The game}

\subsubsection{Timing of the game}

The timing of the game is the following:

(1) All firms $i \in \mathcal{N}$ simultaneously decide how much to invest in research by paying $k(i)$. Simultaneously, each contractor $j \in \mathcal{M}$ posts a price for the task $\tau_{j}$. Let us denote by $\gamma$ the measure of the set of firms investing in technology, i.e. the set $K \equiv\{i \mid k(i)>0\}$

(2) All firms $i \in \mathcal{N}$ simultaneously decide whether to perform the task in-house or to outsource it from an external contractor. In the latter case, a firm also decides which contractor to outsource the task from. Let us denote by $H_{j}$ the set of firms outsourcing from contractor $j$, by $\mu_{j}$ the measure of the set $H_{j}$ and $H \equiv \bigcup_{j \in \mathcal{M}} H_{j}$.

\footnotetext{
${ }^{27}$ The modelling assumptions regarding the information spill are discussed in further detail in Section 6 .

${ }^{28}$ One may wonder why firms investing in technology never generate any information spill, while contractors do if $s>0$. Although it would be possible to introduce in the model a spill generated by firms as well without changing the quality of the results, this paper focuses on the role of contractors as information intermediaries.
} 
(3) Contractors perform the task for their clients and they learn their technologies. Let $\underline{c}_{j}$ be the best technology learned by contractor $j$, i.e. $\underline{c}_{j} \equiv \inf _{\left\{i \mid i \in H_{j}\right\}} c(k(i))$.

(4) Every contractor $j$ decides how much information to sell, i.e. he chooses $c_{j} \in\left[\underline{c}_{j}, 1\right]$ and post a price $\psi_{j}$ for it.

(5) Each firm decides whether to buy technology $c_{j}$ from contractor $j .^{29}$ Let us denote by $B_{j}$ the set of all firms that buy a technology from contractor $j$, let $B \equiv$ $\bigcup_{j \in \mathcal{M}} B_{j}$ and let $\beta_{j}$ and $\beta$ be the measure of the sets $B_{j}$ and $B$, respectively.

(6) The maximum level of technology learned by contractors (i.e., the technology $\left.\underline{c} \equiv \min _{j \in \mathcal{M}} \underline{c}_{j}\right)$ spills to a measure $\sigma=\min [s, n-\gamma-\beta]$ of firms. Each firm in the set $N \backslash(K \cup B)$ receive the spill with probability $\frac{\sigma}{n-\gamma-\beta}$.

(7) Each firm $i \in N$ adopts the best technology it has learned $c(i)$ and decides how much to produce by choosing $q(i) \in R_{+}$. The production is sold on the market and profits are realized.

In this paper I adopt Subgame Perfect Nash Equilibrium (SPNE) as the solution concept, and I focus on pure strategy SPNE.

Remark 1 I refer to the information diffusion by means of the contractors as "information leakage". I also refer to a situation in which some technology diffuses to all firms that did not invest in technology as a "perfect leakage" (i.e. $\beta+\sigma=n-\gamma)$, to a situation in which $0<\beta+\sigma<n-\gamma$ as an "imperfect leakage" and to a situation in which $\beta+\sigma=0$ as "no leakage". Observe that a perfect spill, i.e. $s=n$ (i.e., contractors do not have control over the information) is a sufficient condition to have perfect leakage. In fact, if $s=n$, then I have $\beta+\sigma=n-\gamma$ for any $\gamma$ and $\beta$.

\subsubsection{Payoffs}

The payoff of a generic firm $i \in \mathcal{N}$ on the monopolistic competitive market is:

\footnotetext{
${ }^{29}$ Notice that the model allows firms to hire a contractor to perform the task and a different one to buy information from. Observe also that in this model nothing prevents a firm that invested a positive amount in technology $k$ to buy a better technology later. Since the outcome of the investment is non-stochastic, we never observe such behavior on the equilibrium path.
} 


$$
\pi(i)=[p(i)-c(i)] y(i)-k(i)-\tau-\sum_{h \in \mathcal{M}} \psi_{h} 1_{\left\{i \in B_{h}\right\}}
$$

where $[p(i)-c(i)] y(i)$ is the economic profit, $k(i)$ is the investment in $\mathrm{R} \& \mathrm{D}, \tau$ is the cost paid for the task and $\psi_{h}$ (if any) is the price paid for some technology bought on the market for information. ${ }^{30}$ After solving for the equilibrium on the final product market, because the firms' optimal mark-up rule in this model is $p(i)=\frac{c(i)}{\alpha}$, it is easy to check that

$$
\pi(i)=\frac{W(1-\alpha)}{\int_{\mathcal{N}} c(j)^{\frac{-\alpha}{1-\alpha}} d j} c(i)^{\frac{-\alpha}{1-\alpha}}-k(i)-\tau-\sum_{h \in \mathcal{M}} \psi_{h} 1_{\left\{i \in B_{h}\right\}}
$$

Notice that the profit of firm $i$ is decreasing in the technology level of its competitors. This is because the technology level of the other firms affects the other firms' prices and, via monopolistic competition, the demand that firm $i$ faces on the final product market. ${ }^{31}$

Since the contractors operate at zero marginal cost for the task, the profit for a generic contractor $j \in \mathcal{M}$ is

$$
\pi(j)=\mu_{j} \tau_{j}+\beta_{j} \psi_{j}
$$

where, from the notation introduced before, $\mu_{j} \tau_{j}$ is the revenue generated on the outsourcing market and $\beta_{j} \psi_{j}$ is the revenue generated on the market for information.

\section{The Market for Information}

In this Section I analyze the market for information. First, I derive the demand for information. Then, I explore whether a market for information can arise when $s<n$, and, if it can, to study its structure. If $s<n$, the information that contractors

\footnotetext{
${ }^{30} \mathrm{I}$ denote by $1_{E}$ the indicator variable equal to 1 is the event $E$ occurs and zero otherwhise.

${ }^{31}$ In what follows, when describing the profit of a firm, I will often use the notation $A \equiv$ $\frac{W(1-\alpha)}{\int_{\mathcal{N}} c(j)^{\frac{-\alpha}{1-\alpha}} d j}$.
} 
learn may have a market value, and contractors can find it profitable to sell it to other firms. This happens in the subgames in which the parameters $n, s$ and the (endogenous) measure $\gamma$ of investing firms satisfy $\gamma \in[0, n-s$ ). On the contrary, in the subgames in which $\gamma \in[n-s, n]$, the resulting leakage is perfect, and a market for information cannot arise.

\subsection{Demand for Information}

To analyze the market for information, let us start from the demand side. In this game, the demand for information is endogenous and depends on the number of firms that invested in technology in the initial stage of the game and on the size of their investment. Recall that the set of investing firms has measure $\gamma$. Let us focus now on the set of firms that did not invest in technology. These firms have two ways to learn some technology: first, they could decide to buy it. If a firm buys a technology $c$ from a contractor, this firm will be able to adopt $c$ for sure. Second, each firm could decide not to buy any technology and wait for the information spill $\underline{c}$. If they do so, each firm receives the spill with probability $\frac{\sigma}{n-\gamma-\beta}$. Then, the willingness to pay a technology $c$, that is $\phi(c)$, is the difference between the profit a firm can appropriate by implementing technology $c$ for sure, that is $A c^{-\frac{\alpha}{1-\alpha}}$, and the expected profit the firm can appropriate without buying a technology. Such profit will be $A \underline{c}^{-\frac{\alpha}{1-\alpha}}$ if the firm receives the spill (which happens with probability $\frac{\sigma}{n-\gamma-\beta}$ ), and $A$ if the firm does not (which happens with probability $1-\frac{\sigma}{n-\gamma-\beta}$ ). Formally, the willingness to pay a technology $c \leq 1$ is

$$
\phi(c)=A\left\{c^{-\frac{\alpha}{1-\alpha}}-\left[\frac{\sigma}{n-\gamma-\beta} \underline{c}^{-\frac{\alpha}{1-\alpha}}+\left(1-\frac{\sigma}{n-\gamma-\beta}\right)\right]\right\}
$$

where $A$ is a coefficient that captures how much the market profit of a firm is negatively affected by the technology levels of its competitors. ${ }^{32}$

\footnotetext{
${ }^{32}$ In particular, recall that the profit of a firm with a technology $\widetilde{c}$ is $A \widetilde{c}^{-\frac{\alpha}{1-\alpha}}$, with $A=\frac{W(1-\alpha)}{\int_{\mathcal{N}} c(j)^{\frac{-\alpha}{1-\alpha}} d j}$.
} 


\subsection{The Information Monopolist's Problem}

In this Section, I study the subgames in which firms have already made their investment and outsourcing decisions, they chose the same level of investment and only one contractor has learned this technologies, i.e., the market for information is a monopoly. Moreover, I assume that we are in a subgame in which a market for information can arise, that is $\gamma<n-s$. For these subgames, I study the monopolist's optimal pricing problem. Then, in the next Section, I step back and I solve for the equilibrium of the entire game, showing that, when a market for information arises, we only find such subgames on the equilibrium path.

Observe that when only one contractor learns the technology $\underline{c}_{j}$ (developed by a measure $\gamma$ of firms), he has to make two decisions. In particular, he has to decide the level of the information he wants to sell (i.e., he has to set $c_{j} \geq \underline{c}_{j}$ ) and he has to set a price $\psi_{j}$ for it (or, equivalently, a measure of firms $\beta$ to sell it to). Notice that, in these subgames, the demand for information $\phi$ is affected by the choice variables $c_{j}$ and $\beta$ as follows:

$$
\phi\left(c_{j}, \beta\right)=A\left(c_{j}, \beta\right)\left\{c^{-\frac{\alpha}{1-\alpha}}-\left[\frac{\sigma}{n-\gamma-\beta} \underline{c}_{j}^{-\frac{\alpha}{1-\alpha}}+\left(1-\frac{\sigma}{n-\gamma-\beta}\right)\right]\right\}
$$

where $A\left(c_{j}, \beta\right)=\frac{W(1-\alpha)}{(\gamma+\sigma) \underline{c}_{j}^{\frac{-\alpha}{1-\alpha}}+\beta c_{j}^{\frac{-\alpha}{1-\alpha}}+(n-\gamma-\beta-\sigma)}$. Notice that, as $c_{j} \geq \underline{c}_{j}, \phi\left(c_{j}, \beta\right)$ can be positive only if $n-\gamma-\beta-\sigma>0$, i.e. only if the leakage is not perfect. Also, observe that $\frac{\partial \phi\left(c_{j}, \beta\right)}{\partial \beta}<0$, i.e., $\phi\left(c_{j}, \beta\right)$ is downward sloped in $\beta$. Finally, if $\sigma=0$ the willingness to pay any technology $c_{j}<1$ is positive for any $\beta$. This means that if the control on the information is perfect, firms are always willing to pay a positive amount to acquire any $c_{j}<1$.

Then, the problem of the monopolistic contractor $j$ is to choose $c_{j} \geq \underline{c}_{j}$ and $\psi_{j}$ that solve the following profit maximization problem

$$
\max _{\substack{c_{j} \in\left[\underline{c}_{j}, 1\right] \\ \beta \in[0, n-\gamma-s]}} \beta \phi\left(c_{j}, \beta\right)
$$

Let $\left(c_{j}^{*}, \beta^{*}\right)$ be a solution for the problem (3). Observe that the monopolistic con- 
tractor may have an incentive to limit the "quality" $c$ of the technology sold. In fact, for a given measure $\beta$ of information buyers, the better is the technology contractor $j$ sells (the lower is $c$ ), the lower is $A\left(c_{j}, \beta\right)$, i.e., the higher is the competition on the product market. This tends to decrease the willingness to pay the information. On the other hand, the better is the technology he sells, the lower will be the cost level of the firms who buy the technology from him, and this tends to increase the willingness to pay the information. Once the quality of the technology to sell is fixed, the contractor faces a similar trade-off in deciding his pricing strategy, i.e., in deciding the measure of firms he wants to sell the technology to. Proposition 1 (whose proof is presented in the Web Appendix) shows that the monopolistic contractor always chooses to sell the best technology available, i.e. $c^{*}=\underline{c}_{j}$ and, as long as $s>0$, he never sells it to the entire market, i.e. he never generates a perfect leakage.

Proposition 1 The monopolistic contractor's problem has a unique solution $\left(c^{*}, \beta^{*}\right)$ such that he sells the best technology he learned, i.e. $c^{*}=\underline{c}$ and, if $s>0$, the information leakage he generates is not perfect, i.e. $\beta^{*}<n-s-\gamma$.

The next Corollary (whose proof is presented in the Web Appendix) states that if a monopolistic contractor has perfect control over the information, i.e. if $s=0$, the information leakage he generates is perfect (i.e., $\beta^{*}=n-\gamma$ ). This is due to the fact that if the control of information is perfect, a not investing firm's only way to get a low-cost technology is to buy it from the contractor. This keeps the demand for information relatively high and guarantees the fact that the marginal revenue of information of the monopolist remains positive for any $\beta \in[0, n-\gamma]$. This implies that the monopolist sells the information to the entire market and generates a perfect leakage.

Corollary 2 If $s=0$, the information leakage generated by a monopolist for information is perfect, i.e. $\beta^{*}=n-\gamma$. 


\subsection{Competitive Market for Information}

Let us focus now on a subgame in which several contractors learn the same technology $c$, and a market for information can arise, i.e. $\gamma<n-s$. Then, in such subgame the market for information is competitive, and all contractors post a price for information c equal to zero (i.e., equal to the marginal cost of information). This implies that the resulting information leakage is perfect, i.e. $\beta+s=n-\gamma$. To see this, observe that $c$ is the same technology firms would receive through the spill. Thus, if $\beta+s<n-\gamma$, a firm not buying $c$ on the competitive market would not be sure to learn it through the spill, and would have a profitable deviation in buying it at zero cost. Thus, a perfect information leakage always occurs. The previous observation guarantees the following Lemma:

Lemma 3 In the subgames in which more than one contractor learn the same technology c, a perfect information leakage occurs, i.e., $\beta+s=n-\gamma$.

\subsection{Information Market Structure}

In this Section I show that it is not possible to sustain an equilibrium in which a competitive market for information arises and generates a perfect leakage. As discussed in the previous Section, if the market for information is competitive, the equilibrium price for the technology held by contractors is zero. If there are more than two firms investing and outsourcing from at least two different contractors, at least one firm has a profitable deviation in not investing and waiting to buy such technology at a zero price. Then, the number of investing and outsourcing firms in such equilibrium has to be exactly two, and they outsource from two different contractors. If this is the case and $s>0$, from Proposition 1 we know that one of these firms has a profitable deviation in outsourcing from the same contractor of the other. This is because if $s>0$, this contractor would generate an imperfect leakage instead of a perfect one. Proposition 4 (whose proof is presented in the Appendix) formalizes these considerations, and states that in equilibrium the market for information is never competitive. 
Proposition 4 All the firm that invest in equilibrium outsource from the same contractor. Thus, when a market for information arises in equilibrium, it is always a monopoly.

Proposition 4 offers a key prediction of this model. Despite the fact that the original outsourcing market is perfectly competitive, if a market for information arises in equilibrium, it is always the case that this market is a monopoly.

The result of Proposition 4 has a very general intuition and it is very robust to different specifications of the model. ${ }^{33}$ Proposition 4 says that information leakage concerns tend to concentrate the outsourcing market with respect to the structure it would have otherwise. This is because when a high-tech firm has to choose the contractor to hire, it will anticipate the impact of its decision on the downstream market for information. If it hires a contractor that has a critical mass of other hightech clients (say, contractor $j$ ) rather than a contractor with no or fewer other hightech clients (say, contractor $h$ ), the high-tech firm accomplishes two results. First, the information the firm will bring to contractor $j$ is negligible as the contractor is already collecting information from all his other clients, while the same information would be very relevant for contractor $h$. Second, by hiring contractor $j$, the firm preserve a high concentration on the downstream market for information. If the firm hired contractor $h$ instead, contractor $h$ would become a stronger competitor on the market for information for contractor $j$. As a result, the price for information would decrease and the information leakage would increase. ${ }^{34}$

\footnotetext{
${ }^{33}$ The robustness of this result to several modifications of the model is discussed in the Web Appendix.

${ }^{34}$ The extension of the model with complementary innovations (introduced in Footnote 26) adds a trade-off from the point of view of the firms when choosing a contractor: the more concentrated the market for information is, the smaller the set of firms that will buy information on the market. On the other hand, the more concentrated the market for information is, the better the technology sold on such market. If the complementarities are low enough, all our results still hold. Notice that this extension will make the monopolistic surplus on the market for information, and thus the willingness to pay of the contractors to become the monopolist, higher than in the model presented in the paper.
} 
In the next Section, I identify the conditions under which a monopolistic market for information is indeed an equilibrium outcome of the game.

\subsection{Equilibrium analysis}

\subsubsection{Equilibrium if $s>0$}

In this Section I analyze the case $s \in(0, n)$, i.e. the contractors do not have full control of the information they hold, but the spill is not perfect.

If $s \in(0, n)$, the structure of the equilibria changes as $s$ crosses a cut-off level $\bar{s}$. In the next result (whose proof is presented in the Appendix), I show that if $s$ is positive but small enough, there is a unique SPNE in which a market for information arises.

Proposition 5 There is $\bar{s} \in(0, n)$ such that if $s \in(0, \bar{s})$ there is a unique equilibrium in which a set of measure $\gamma_{m i}>0$ of firms invest $k_{m i}>0$ in technology, a set of measure $\beta_{m i}>0$ of firms buy the information, and a set of measure of firms $n-\gamma_{m i}-\beta_{m i}>s$ receive the spill or produce at the highest cost level. In this equilibrium all the investing firms outsource from the same contractor.

Proposition 5 guarantees the existence (and uniqueness) of an equilibrium in which a market for information arises. In this equilibrium the firms are divided into two main sets: the firms that invest $k_{m i}>0$ in technology, and the firms that do not. A crucial feature of this equilibrium is that, by Proposition 4, all investing firms outsource the task from the same contractor. This, together with Proposition 1, guarantees that an imperfect leakage is generated, i.e. the information is not going to diffuse to the entire market. Thus, the set of the firms that do not invest in technology is divided into three subsets: the firms that buy technology $c_{m i}=$ $\left(1+k_{m i}\right)^{-\rho}$ from the contractor, the firms that learn this technology through the spill and the set of firms that remain without any technology.

In equilibrium, firms have to be indifferent between investing and not investing in $R \& D$. If they invest in $R \& D$, they bear the cost of the investment but they are 
sure to produce at a low cost level. On the other hand, if they do not invest and they buy the technology from the contractor, they produce at low costs (but the contractor appropriates the surplus from a low-cost production). If they do not buy the technology, with some probability they receive the spill and are able to carry out production at a low cost level. If they do not receive the spill, they produce at the highest possible cost level. As it is illustrated in the Appendix, the indifference condition between investing and not investing identifies the equilibrium measure of investing firms, i.e. $\gamma_{m i}$.

For this equilibrium to exists, the spill $s$ cannot be higher than the upper bound $\bar{s}$. Such upper bound is identified by the condition that, if a zero-measured set of firms invest in technology, investing in technology represents a positive deviation for a not investing firm. ${ }^{35}$

Notice that the equilibrium under consideration does not require contractors to be more efficient than firms in performing the task, i.e. $t$ does not need to be large for a market for information to arise. In particular, as all firms in this equilibrium outsource, the structure of this equilibrium is independent on the parameter t. Thus, even in a market populated by contractors that are as efficient as in-house production (i.e., $t=0$ ), one of them can emerge as the monopolist of the market for information. ${ }^{36}$

To conclude the analysis of the equilibrium with a market for information, let us focus on the observable and derive some implications on the structure of this market. In the equilibrium described in Proposition 5, the market segments into four different sets of firms: the ones which invest in technology, the ones who buy

\footnotetext{
${ }^{35}$ It is easy to show that if $s \in[\bar{s}, n)$, two cases are possible. If $t \geq \widetilde{T}$, we still have an equilibrium in which a monopolistic market for information arises as at most one firm invests in technology and outsources. A second firm cannot invest and outsource since it would have a profitable deviation in not investing. If $t<\widetilde{T}$, only no leakage equilibria, similar to the $s=n$ case one, are possible.

${ }^{36}$ Of course, this is because with the extremely simple information aggregation assumptions we have, every single firm does not have any impact on the knowledge of the monopolistic contractor. Still, even in a situation in which every firm's technology has a (decreasing) impact on the knowledge of the contractor, we could support a similar equilibrium for an arbitrarily low $t$.
} 
technology, the ones which receive the technology through the spill and the ones which end up producing without a technology. Notice that, because of the simplicity of our assumptions, in equilibrium the first three sets will produce at the same cost level, so they will have the same technology, the same marginal costs and the same production level. While the profit of the firms belonging to the first two sets is the same (in equilibrium the firms are indifferent between investing and buying the technology from the contractor), the profts of the firms which receive the spill $e x$ post are higher (they realize the same profits of the previous two on the market, but they receive the technology for free). Of course, the firms which end up without a technology will produce less at a higher marginal cost, and ex-post will have the lowest profits and production level on the market.

\subsubsection{Borrowing constraints}

Contractors face a two-stage market. First, they compete in the outsourcing market, and then, in the market for information. The competition among them guarantees that no surplus from the outsourcing market can be appropriated by any of them. However, in the equilibrium analyzed in Proposition 5, there is a potential surplus to be realized in the market for information, i.e. $\beta_{m i} \phi\left(c_{m i}, \beta_{m i}\right)$. In this equilibrium, the competition among contractors drives the appropriation of that surplus to zero as well. In fact, the contractor that becomes the information monopolist anticipates to appropriate the surplus of the market for information. This implies that contractors compete to be in that position when they post the price for the task. In other words, contractors are willing to run a deficit in the first stage of the game to appropriate the surplus in the second stage.

However, contractors may find difficult to get the liquidity necessary to run such deficit in the first stage. In this model, a borrowing constraint for contractors amounts to requiring the price of the task to be non-negative.

Definition 1 There is a borrowing constraint in the outsourcing market if no contractor can post a negative price for the task, i.e. $\tau_{j} \geq 0$ for all $j \in\{1, . ., m\}$. 
If a borrowing constraint is present in the outsourcing market, one contractor appropriates all the surplus generated in the market for information. In fact, if the contractors cannot lower the price of the task below zero, all investing firms will outsource from the same contractor, say $j$, for $\tau(j)=0$. This implies that such

contractor appropriates the entire market for information surplus $\beta_{m i} \phi\left(c_{m i}, \beta_{m i}\right)$. This result is formalized in Corollary 6 .

Corollary 6 If $s \in(0, \bar{s})$ and there is a liquidity constraint in the outsourcing market, one contractor appropriates all the market for information surplus, i.e. he realizes the profit $\beta_{m i} \phi\left(k_{m i}, \beta_{m i}\right)$.

\subsubsection{Equilibrium if $s=0$}

In Corollary 2 I already started studying the case in which contractors have a perfect control over information, i.e. $s=0$. In this case, there is no information spill and all the firms that neither invest in R\&D nor buy the information from the contractor always produce at the maximum cost level. Corollary 2 states that if $s=0$, the notinvesting firms are always willing to pay a positive amount to get the information from a contractor. This keep the demand for information high enough to guarantee that a monopolistic contractor always generates a perfect leakage. In Proposition 7 (whose proof is presented in the Web Appendix), I analyze the implications of perfect information control on the equilibria of the game.

Proposition 7 If $s=0$ there is a unique equilibrium in which all firms outsource and invest $k_{0} \geq 0$ in technology. No firm buys information from a contractor.

Proposition 7 guarantees that if $s=0$, no market for information arises. This is due to the fact that the optimal investment problem that investing firms solve when deciding how much to invest guarantees that the total return on the optimal investment is strictly positive. This implies that no firm can find it optimal to buy the information from the contractor (who extracts all the surplus generated by R\&D in the transaction), rather than to invest at the beginning of the game. Proposition 
7 suggests that when information sellers have perfect control over the information they sell, they face a hold-up problem generated by the lack of commitment power on the price for information.

\section{$4 \quad$ Perfect spill $(s=n)$}

In this Section I analyze the situation in which contractors do not have any control over the information they learn from their clients. This situation corresponds to the particular case of the model in which $s=n$. This case fits situations in which, for instance, the market geographical concentration and the labor mobility are very high (e.g. Silicon Valley), or the contractors are not sophisticated enough to market the information they hold.

To start the analysis of the perfect leakage case, observe that if $\underline{c}_{j}$ is the best technology learned by contractor $j$ from his clients, each firm on the market has the choice to adopt the technology $\underline{c} \equiv \min _{j \in \mathcal{M}} \underline{c}_{j}$ at no cost. This implies that there can be no market for information, as firms know that they are going to receive the spill and learn the best technology for free.

The following Lemma (whose proof is presented in the Web Appendix) guarantees that, if $s=n$, none of the outsourcing firms can invest in technology in equilibrium.

Lemma 8 If $s=n$, no outsourcing firm invests in equilibrium.

To understand the intuition of Lemma 1, notice that the competition among contractors and the absence of a market for information guarantees that the price charged for the task is always $\tau_{j}=0$ for all $j \in \mathcal{M}$. Let us analyze the choices of the firms about technology investment and outsourcing. Since $\tau_{j}=0$ for all $j \in \mathcal{M}$, it is obviously the case that if a firm does not invest in $R \& D$, it always outsources (as there is no cost associated with hiring a contractor). Suppose that there is a nonempty set of firms outsourcing and another non-empty set of firms not outsourcing. If one of the outsourcing firms invests in technology, no other firm in the same set can invest in equilibrium as they anticipate receiving the leakage for sure. This implies 
that no more than one firm among the outsourcing ones can invest in equilibrium. Now, is it possible to have an equilibrium where exactly one outsourcing firm also invests some positive amount in technology? In this case, since this firm has to pay the cost of the investment in technology and all the others free-ride on the investment, this firm has a payoff lower than any other outsourcing firm. On the other hand, in equilibrium it must be the case that outsourcing and not outsourcing firm have the same payoffs. Thus, the only investing and outsourcing firm would have a profitable deviation by not outsourcing. This implies that in equilibrium it must be the case that all the outsourcing firms operate at the maximum cost level, i.e., they do not invest in technology. This guarantees that, if $s=n$, research is carried out only in non outsourcing firms.

The next Proposition (whose proof is presented in the Web Appendix) describes the pure strategies equilibria in the perfect leakage case.

Proposition 9 If $s=n$, there exist $\bar{T}$ and $\underline{T}$ such that $\bar{T}>\underline{T}$ and: (i) if $\bar{T} \leq t$ in the unique SPNE all firms always outsource and there is no investment. (ii) if $\underline{T}<t<\bar{T}$, then there is a unique SPNE in which a positive measure of firms $\gamma_{n}$, invest $k_{n}>0$ and do not outsource, and a positive measure of firms, $n-\gamma_{n}$, outsource and do not invest. (iii) if $t \leq \underline{T}$, there are no pure strategy equilibria.

Proposition 9 guarantees that if $s=n$, there is never information leakage in equilibrium. Proposition 9 (i) states that if the advantage from outsourcing is high enough (i.e. if $t$ is higher than the upper bound $\bar{T}$ ), all firms outsource from contractors and, by Lemma 1, no firm can invest in equilibrium.

Proposition 9 (ii) describes the "no leakage" equilibrium. In this equilibrium the market splits into two separate segments of firms. The firms in the first set invest in technology and never outsource, while the ones in the second set do not invest and outsource. For this equilibrium to exist, the measure of these two sets of firms has to guarantee the equality of the profits of the firms within each group. As it is shown in the Web Appendix, there is a unique measure $\gamma_{n}$ which satisfies such condition. This equilibrium occurs if $t$ is in between the two bounds $\underline{T}$ and $\bar{T}$. The condition 
of $t$ being lower than $\bar{T}$ rules out the equilibrium in point (i), since it guarantees that if all firms outsource and do not invest, one firm has a profitable deviation in investing in technology and performing the task in-house. On the other hand, $t$ being higher than $\underline{T}$ guarantees that in the case in which a $n$-measured set of firms do not contract and invest, outsourcing and not investing represents a profitable deviation.

Proposition 9 suggests that if the outsourcing market is populated by contractors who have very scarce control over the information they have, we should not observe information leakage. In particular, depending on the efficiency level of the contractors, we should observe cases in which all firms outsource and the market is characterized by low $R \& D$ investment levels and cases in which the market splits into a set of low-tech firms that outsource and a high-tech set of firms which do not.

In terms of observables, in the "no leakage" equilibrium described in Proposition 9 , the firms that invest and do not outsource will produce more (at a lower marginal cost), while the firms that do not invest will produce less (at a higher marginal cost). The economic profits (not including the R\&D investment) will be higher for the first set of firms.

\section{Comparative statics and welfare implications}

\subsection{Comparative Statics}

In Sections 3 and 4, I analyzed the equilibria arising as $s$ varies in the interval $[0, n]$. Recall that the parameter $s$ measures the amount of control a contractor has over the information he learns from his clients. In a situation in which $s=n$ a contractor cannot become an information seller. A contractor can become an information seller only when he becomes aware of the information he holds, he protects and controls it to some extent and he has the ability to market and sell it to other firms. In our model this corresponds to a situation in which $s$ is small enough. When contractors reach full control of the information they hold, we are in a situation in which $s=0$. 
It is interesting to analyze the change in the level of technology developed by the investing firms and the change in the diffusion of such technology in the market as the parameter $s$ varies from $n$ to 0 , i.e. as contractors have more and more control over the information they hold.

When contractors have no control over the information they hold, i.e. when $s=n$, Proposition 9 shows that there exists a not-empty interval $[\underline{T}, \bar{T}]$ such that if $t \in[\underline{T}, \bar{T}]$ there is a unique pure strategy equilibrium where a positive measure of firms invest and do not outsource. Recall that we named as $k_{n}$ and $\gamma_{n}$ the (maximum) investment level in such equilibrium and the measure of firms that carry it out, respectively. Recall also that in such equilibrium there is no information leakage. This implies that only the firms that invest have a low-cost technology. ${ }^{37}$ When $s \in(0, \bar{s})$, I showed that a perfect leakage never occurs in equilibrium, and there is an equilibrium in which a market for information arises. Recall that $k_{m i}, \gamma_{m i}$ and $\beta_{m i}$ are the investment carried out by the investing firms in such equilibrium, the measure of firms that carry it out and the measure of firms that buy the technology, respectively. Notice that the total measure of firms adopting the technology developed by the investment $k_{m i}$ in such equilibrium is $\gamma_{m i}+\beta_{m i}+s$. Finally, when $s=0$, I showed that in the unique equilibrium all firms invest $k_{0}$ in R\&D (using a notation consistent with the other cases, let $\gamma_{0}=n$ ). Proposition 10 (whose proof is presented in the Web Appendix) compares the maximum investment levels and the measure of the diffusion that the technologies reach as the parameter $s$ varies.

Proposition 10 The equilibrium maximum investment levels are such that $k_{n}>$ $k_{m i}>k_{0}$. The measures of firms adopting such technologies are such that $\gamma_{n}<$ $\gamma_{m i}+\beta_{m i}+s<\gamma_{0}=n$.

Proposition 10 describes the effect of an increased sophistication of contractors as information sellers on the technology maximum level and diffusion in the market. When contractors do not have any control of the information that they hold the

\footnotetext{
${ }^{37}$ When $t>\bar{T}$, we showed that there is a unique equilibrium in which all firms outsource and no firm invests. Thus, $k_{n}$ is the highest R\&D investment in any pure strategy equilibrium for $s=n$.
} 
level of technology reached in equilibrium is the maximum one. However, such information is adopted by the minimal possible measure of firms. A decrease in $s$ depresses the maximum level of technology, but increases the size of the set of firms that adopt such technology. Finally, if contractors have full control on the information, the level of technology is the minimal possible and everybody adopts it.

Notice that this comparative statisc have an implication on the distribution of output. If $s=n$, the industry is segmented into high-output and low-output firms. As $s$ decreases, the distribution of the output (and the economic profits) in the industry becomes more and more uniform. As $s$ varies, the distribution of the total profit in the industry changes in a non-monotonic way. If $s=n$, all firms in the industry have the same total profits. As $s$ decreases, we observe in equilibrium firms that free-ride (through the spill) on the R\&D of other firms, and have the highest total profits in the industry. When $s=0$, the distribution of the total profit is uniform again.

Another interesting comparative static exercise is to see how the equilibria structure changes if the size of the market $n$ increases. To discuss the implications of a change in $n$, observe first that, by Assumption 2, the size of $n$ is bounded above by $W \alpha \rho$. Assumption 2 is a sufficient condition to guarantee that in equilibrium (unless they anticipate free-riding on the investment made by someone else) firms invest in R\&D. Removing Assumption 2 and letting $n$ grows arbitrarly large, eventually causes firms to stop investing in R\&D (because the returns on $R \& D$ would be too small), and the information leakage costs of outsourcing disappearing. So, all firms will always outsorce and no R\&D information will be shared or sold. ${ }^{38}$ Suppose now that $n$ increases in the range $[0, E \alpha \rho]$ The implications of an increase in the market size $n$ is described in the following Proposition, whose proof is presented in the Web Appendix.

\footnotetext{
${ }^{38}$ Interstingly, this implies that if the markets increase dramatically, the outsourcing market will explode (at a rate even higher than the rate of growth of the product markets). This seems to be consistent with the evidence of market globalization.
} 
Proposition 11 As $n$ increases, (i) if $s=n$, in the "no-leakage equilibrium" $\gamma_{n}$ decreases. (ii) if $s \in(0, \bar{s}), \gamma_{m i}+\beta_{m i}$ decreases.

While Proposition 11 provides the directions of change of the measure of investing firms as $n$ increases, similar conclusions for the investment levels $k_{n}$ and $k_{m i}$ are not so straightforward. Indeed, Proposition 11 suggests that the equilibrium investment levels $k_{n}$ and $k_{m i}$ are affected by two competing effets as $n$ increases. First, since $n$ increases, there is a direct effect on the price level of the firms that tends to depress $k_{n}$ and $k_{m i}$. On the other hand, as in equilibrium $\gamma_{n}$ and $\gamma_{m i}+\beta_{m i}$ decrease, there is a indirect effect such that, since the measure of the firms investing decreases, the returns on investment of an investing firm could be overall higher. ${ }^{39}$

\subsection{Welfare Implications}

Several inefficiency arise in the model presented in this paper. In particular, in the equilibria described in Sections 3 and 4, we observe duplication of $R \& D$ investment, inefficient investment level and monopolistic pricing. A general discussion on the welfare implications of this model is not straightforward because we do not always have closed-form solutions for the measure of investing firms in equilibrium. However, here we characterize the first-best and use this characterization to find sufficient conditions under which the presence of a market for information is strictly efficiency improving.

As usual in these models, in order to find the first best, we think about the $\mathrm{R} \& \mathrm{D}$ investment as funded by the representative consumer through a lump-sum tax. The investment should be paid just once, and the technology should be diffused to all firms, which always outsource and are left free to set the price they want. Since it is possible to show that, if all firms have the same marginal cost level, the aggregate profit of the firms is independent from it, the social planner will choose the investment level $k^{f b}$ which maximizes the utility of the consumer $u(k)=$

\footnotetext{
${ }^{39}$ While I conjecture the latter to be a second order effect, this could be an interesting direction for investigation. I expand this point for further research in Section 6.
} 
$(E-k)+W \ln \left[\int_{0}^{n} y(i, k)^{\alpha} d i\right]^{1 / \alpha}$, that is $k^{f b}=W \rho-1$. In a framework without information leakage, every firm invests $k^{n l}=\frac{W \alpha \rho}{n}-1$. This outcome is inefficient because of the duplication of investment and also because $k^{n l}<k^{f b}$ if $\alpha<n$ (underinvestment case) and $k^{n l}>k^{f b}$ if $\alpha>n$ (overinvestment case). The question is whether the presence of information diffusion and the possibility for a market for information mitigates the inefficiency in the underinvestment case $(\alpha<n) .{ }^{40}$ Suppose that the measure of firms adopting a technology is $\lambda$. Then, the optimal investment level of an investing firm is a decreasing function of $\lambda$. It is easy to show that if no other firm adopts a technology, the optimal investment level is $\widehat{k}=\left(\frac{W \alpha \rho}{n}\right)^{\frac{1-\alpha}{1-\alpha-\alpha \rho}}-1$. If $\widehat{k} \leq k^{f b}$, then the presence of information leakage, besides mitigating the duplication problem, can bring the investment in technology closer to the first best. ${ }^{41}$ This will happen every time in equilibrium the measure of investing firms is $\lambda<n$.

Let us now address the question of whether the introduction of a market for information is efficiency-improving. We know that when $s=0$, a market for information does not arise in equilibrium, so the duplication is as severe as in the framework without information leakage $\left(\gamma_{0}=n\right)$ and the investment level is the same (i.e. $k_{0}=\frac{W \alpha \rho}{n}-1$ ). If $s=n$, as we discussed in Section 4 , a market for information does not arise in equilibrium either. However, for $s \in(0, \bar{s})$, we know that a market for information can arise in equilibrium. This is beneficial from the duplication of investment point of view and, in the conditions we discussed above, this also brings the investment level closer to the first best. ${ }^{42}$ So, under these conditions the presence

\footnotetext{
${ }^{40}$ The optimal investment level for a firm decreases as the measure of firms that adopt the same technology increases. Thus, if $\alpha>n$ the overinvestment problem cannot be solved by the presence of information leakage. However, the presence of information leakage still mitigates the duplication of investment.

${ }^{41}$ The condition $\widehat{k} \leq k^{f b}$ is satisfied if $\left(\frac{\alpha}{n}\right)^{\frac{1-\alpha}{1-\alpha-\alpha \rho}}<(W \rho)^{\frac{-\alpha \rho}{1-\alpha-\alpha \rho}}$. Notice that $\widehat{k} \leq k^{f b}$ is a sufficent, but not necessary condition for information leakage to be efficiency-improving. Indeed, if $\widehat{k}>k^{f b}$, we could still have an intermediate level of technology to be closer to the first best than $k^{n l}$.

${ }^{42}$ Notice that, in the absence of a market for information, for small $s$ the equilibrium would tend to look similar to the one in which $s=0$.
} 
of a market for information is strictly efficiency improving.

\section{Discussion and further research}

\subsection{Information sellers}

An important feature of the model presented in Section 2 is the fact that firms cannot participate directly in the market for the information by selling their technology to competitors. This assumption allows to simplify the analysis of the game and to focus on the role of contractors as information intermediaries.

In reality, we sometimes observe firms that trade technologies with their competitors through licencing. In this paper I focus on technologies whose implementation is difficult to monitor (such as cost-cutting technologies) and on which Intellectual Property Rights are harder to enforce. Firms are less likely to start diffusing such technologies through licences, as a further diffusion on the market is hard to prevent. Also, if an innovative firm can choose on which markets they want to sell their technologies, they are more likely to choose markets that are not populated by their direct competitors. This imples that firms are less likely to participate their market directly as information sellers.

Let us discuss the consequences of removing such assumption from the model. If one considers a market for information populated both by contractors and firms, the reliability of information sold by contractors is likely to be considered by potential customers higher than the one sold by their own competitors. This is because firms may have incentives to distort the information to damage their competitors on the product market (and thus, via monopolistic competition, to stimulate their own demand). On the other hand, contractors do not participate in the competition on the product market, and they do not have incentives to distort the information they sell. Thus, in order to sell information to a rival, a firm may have to incur an extra cost to certify the information and convince the buyers to make the purchase. When this cost is big enough, the main results of this paper still hold. If such cost is 
small or non-existent, with the model presented in this paper, it is easy to check that sometimes (for instance, for $s=0$ ), the existence of a pure-strategy equilibrium may fail. ${ }^{43}$ Notice however that this problems are mainly due, via Proposition 4 , to the extreme characteristics of the Bertrand competition on the market for information. Other modules of competition on the market would make the magnitude of the leakage sensitive to the number of participants on the market for information when this number is higher than 2. Then, the main intuition of our results, that is, the possibility that contractors generate an information leakage tends to make the outsourcing market more concentrated of how it would be otherwise, would still hold.

\subsection{Information spill}

A second feature of the model worthwhile discussing here is the presence and the features of the information spill. Here, I first discuss the presence of the information spill in the model, and then I discuss its features in the modelling choices made in Section 2.

As discussed in Section 3, the presence of a positive information spill guarantees that in equilibrium not all the firms invest in R\&D.

As it is apparent from the description of the timing of the game, an important assumption of this model is the fact that firms have to decide whether to invest in technology and whether to buy technology before knowing whether they receive the information spill. This is because the information spill is a phenomenon that should be interpreted as taking place in the long-run: as contractors experience labor turnover, the technologies start diffusing through the market and more and more firms start adopting it.

\footnotetext{
${ }^{43}$ This is because, as arguments very similar to the ones made for Proposition 4 apply here as well, competition on the market for information difficult to sustain in equilibrium. Then, the only situation possible to be sustained as equilibrium would be the one in which only one firm invests and sells the information to the rest of the market (with some spill $s>0$ to deter the other firms from investing themselves rather than wait for the information leakage).
} 


\subsubsection{Spill Modelling Features}

Finally, let us discuss the assumption that the spill can be received only by firms that neither invest in technology nor bought information from contractors, that is the measure of firms receiving the spill is $\sigma=\frac{s}{n-\gamma-\beta}$. This assumption is made to guarantee that, in a market in which all the firms (but a zero-measured set) are adopting a certain technology, the firms that are not adopting it will learn it through the spill with probability one, and are thus willing to pay zero to buy it from a contractor (formally, $\phi(c, n-\gamma-s)=0$ ). In this model, this is necessary to guarantee that, as it is natural to expect from a monopolist, the contractor will not sell the information to all firms that did not invest in $\mathrm{R} \& \mathrm{D}$, but will keep the price for information high enough to leave some firm without technology on the market.

While I mantained the functional form of the spill $\sigma=\frac{s}{n-\gamma-\beta}$ for simplicity, it is easy to guess that all the results could have been achieved with more general assumptions. For instance, if we assume that any firm on the market receives some spill with a probability $\widetilde{\sigma}$ that is increasing in the measure $\gamma+\beta$ of firm already adopting the same technology, with this probability going to 1 as $\gamma+\beta$ tends to $n$, the analysis will be substantially more cumbersome, but this not affect the intuition of the results in any significant way.

As an example to justify the fact that the probability of receiving the spill increases if $\gamma$ and/or $\beta$ increase, think about the example of spill due to high labor turnover. As $\gamma$ and/or $\beta$ increase, this means that there are more high-tech firms present on the market, and then more high-tech employees that could change job in the future. This results in a higher probability for all firms in general (and low-tech firms in particular) to hire high-tech employees and then to receive exposure to the spill.

\subsection{Further research}

The model presented in this paper could be employed to explore several interesting directions of future research.

First, there is an ongoing debate on what will be the impact of the recent global 
outsourcing trends on R\&D improvement. In particular, a concern regarding global outsourcing is the general lack of Intellectual Property enforcement in many countries where global outsourcing takes place. Our case of $s=n$ is a natural fit to explore the impact of contractors located in countries where intellectual property is not enforced and information leakage impossible to monitor. It would be interesting to understand, in the $s=n$ case, what is exactly the impact of a market expansion (increased $n$ ), or an increase in competitivity (increased $\alpha$ ) on the R\&D equilibrium level $k .^{44}$

Second, in this model I assumed that a contractor working for a firm always perfectly learns the technology developed by the client. This is obviously a strong assumption, and it is due to the fact that the focus of this paper is to understand the implications of the ability of the contractors (captured by the parameter $s$ ) as information sellers, and not the access they happen to have to the technologies of their clients. An alternative version of this model is a situation in which a contractor hired by a firm learns the technology with some probability $\alpha \in(0,1)$. The parameter $\alpha$ captures the degree to which cost-cutting technology may be transferred or copied, and it varies across industries. One can show that is contractors have no information control (i.e., $s=n$ ), in equilibrium an interesting phenomenon arises: the market segments into three sets of firms: a positive-measured set of firms that invest in R\&D and do not outsource, a positive-measured set of firms that do not invest in R\&D and outsource and a finite number of firms that both outsource and develop R\&D technology. It is interesting to note that, in the early 90s, Sun Microsystems was outsourcing most of its production; however, it was still able to innovate and compete effectively, both with workstation manufacturers who, by and large, were not outsourcing but were also investing in R\&D (e.g. HP), and with "second-tier" firms who did not invest in R\&D and relied on outside contractors. The proposed extension of the model seems to capture this situation quite well. By

\footnotetext{
${ }^{44}$ Proposition 11 already suggests that the measure of firms carrying out innovation decreases as $n$ increases. In Section 5, I briefly discussed the competing effects that determine the impact on $k$.
} 
making the parameter $\alpha$ vary, one can derive testable predictions about the structure of industries which differ in the possibility to replicate cost-cutting technology. Also, one may try to predict which of these industries are likely to display a higher reliance on outsourcing in general and management consultants in particular. 


\section{Appendix}

Proof of Proposition 4: First of all, notice that the competition on the contractor market guarantees $\tau_{j}=\tau_{h}$ for all $j, h \in \mathcal{M}$.

Suppose there is a SPNE in which there is a competitive market for information. This implies that there are at least two investing firms that outsource from two different contractors. If the firms are more than two, there is at least one firm that would have a profitable deviation in not investing and buying the technology at zero price. This implies that there can only be exactly two investing firms outsourcing from two different contractors. However, by Proposition 1, if $s>0$, one of these two firms would have a profitable deviation hiring the same contractor of the other firm, as this would produce an imperfect leakage instead of a perfect one. To conclude the proof, it remains to show that we cannot have a competitive market for equilibrium with $s=0$. To see this, observe that if there are more than two firms investing and outsourcing from different contractors, one would have a profitable deviation in waiting to buy the information for free. Then, there must be at most two firms investing and outsourcing from two different contractors, say A and B. The price of the task in this situation has to be the same for both firms, say $\widetilde{\tau}$. Let $S$ be the surplus on the market for information that a monopolist would appropriate. If $\widetilde{\tau}>-S$, contractor A would have a profitable deviation in lowering the price of the task to $\widetilde{\tau}-\varepsilon$ to attract the client of contractor $\mathrm{B}$, become the information monopolist and appropriate $S$ later. If $\widetilde{\tau}=-S$, then one of the two contractor would have a profitable deviation in raising the price of the task (or equivalently, drop out of the market), as he is not going to appropriate $S$, and he is offering the task at a negative price

\section{Proof of Proposition 5:}

First step: Let us show that if in equilibrium there are more than one firm that outsource and invest in R\&D, then all firms outsource. To see this by contradiction, suppose that more than one firm contract and invest, and someone does not outsource. From Proposition 4 we know that all the investing firms must outsource from the same contractor, say $j$. Since all the outsourcing and investing firms face the same decision problem, in equilibrium they have to invest the same. This implies that none of the the 
outsourcing firms is adding any information to the level of knowledge of contractor $j$. Thus, the outsourcing and the not outsourcing firm face the same problem when deciding how much to invest.

Since $\tau$ is a constant, we have that all the firms invest the same. This implies that the non outsourcing firms would be better off outsourcing, since, with other firms already outsourcing and investing, they would not affect the information learned by the contractor, and then the quality and size of the leakage.

Second step: We have to build an equilibrium in which $\gamma_{m i}$ firms invest and outsource from the same contractor, $\beta_{m i}$ firms buy the technology from this contractor and $s<$ $n-\gamma_{m i}-\beta_{m i}$ firms receive the spill. First of all, notice that the competition on the contractor market guarantees $\tau_{j}=\tau_{h}$ for all $j, h \in \mathcal{M}$. If a set of measure $\gamma_{m i}$ of firms invest and outsource from a contractor, observe that an investing firm is better off hiring the same contractor (this is because, from Proposition 1 we know that if the market for information is a monopoly the leakage is not perfect, while competitive market for information would produce a prefect leakage). For this equilibrium to exist, three conditions need to be satisfied. First, it must be the case that the firms that invest have the same expected profit of the firms that do not invest. Second, the equilibrium investment $k_{m i}$ has to be the optimum one for the investing firms and finally the price for information and the measure of firms buying information $\left(\beta_{m i}\right)$ have to be the profit maximizing ones for the monopolist of information, say contractor $j$. Given $\gamma$, from the information monopolist's problem, from Proposition 3 and from the optimal investment problem we know that $c^{*}(\gamma) \equiv\left(1+k^{*}(\gamma)\right)^{-\rho}$ and $\beta^{*}(\gamma) \in(0, n-s-\gamma)$ satisfy

$$
\beta^{*}=\underset{\beta \in[0, n-s-\gamma]}{\arg \max } \frac{\beta \frac{n-\gamma-\beta-s}{n-\gamma-\beta}}{(\gamma+s+\beta)\left[\left(1+k^{*}\right)^{\frac{\alpha \rho}{1-\alpha}}-1\right]+n}
$$

(where we know from Proposition 3 that $\beta^{*}<n-s-\gamma$ ) and

$$
\frac{W \alpha \rho\left(1+k^{*}\right)^{\frac{\alpha \rho-1+\alpha}{1-\alpha}}}{\left(\gamma+s+\beta^{*}\right)\left[\left(1+k^{*}\right)^{\frac{\alpha \rho}{1-\alpha}}-1\right]+n}-1=0
$$

Now, we need to find $\gamma$ such that the expected profits of the investing firms, i.e. $\pi_{\mathcal{I}}$ is the same as the one of the not-investing firms, i.e. $\pi_{\mathcal{N} \backslash \mathcal{I}}$. For this to be true, $\gamma$ has to 
satisfy

$$
\begin{aligned}
\pi_{\mathcal{I}}(\gamma) & =A(\gamma)\left(1+k^{*}(\gamma)\right)^{\frac{\alpha \rho}{1-\alpha}}-k^{*}(\gamma)= \\
& =A(\gamma)\left\{1+\frac{s}{n-\beta^{*}(\gamma)-\gamma}\left[\left(1+k^{*}(\gamma)\right)^{\frac{\alpha \rho}{1-\alpha}}-1\right]\right\} \\
& =\pi_{\mathcal{N} \backslash \mathcal{I}}(\gamma)
\end{aligned}
$$

where

$$
A(\gamma)=\frac{W(1-\alpha)}{n+\left(\gamma+\sigma+\beta^{*}(\gamma)\right)\left[\left(1+k^{*}(\gamma)\right)^{\frac{\alpha \rho}{1-\alpha}}-1\right]}
$$

Notice that if $\gamma=n-s$, we have that $\beta^{*}(n-s)=0$. On the other hand, we have that $k^{*}(n-s)>0$. In fact, the optimal investment $k$ in this case satisfies

$$
\frac{W \alpha \rho}{n(1+k)^{\frac{\alpha \rho}{1-\alpha}}}(1+k)^{\frac{\alpha \rho-1+\alpha}{1-\alpha}}-1=0
$$

Then, we have $k^{*}(n-s)=\frac{W \alpha \rho}{n}-1>0$ by Assumption 2. This implies

$$
\begin{aligned}
\pi_{\mathcal{N} \backslash \mathcal{I}}(n-s) & =A(n-s)\left(1+k^{*}(n-s)\right)^{\frac{\alpha \rho}{1-\alpha}} \\
& >A(n-s)\left(1+k^{*}(n-s)\right)^{\frac{\alpha \rho}{1-\alpha}}-k^{*}(n-s) \\
& =\pi_{\mathcal{I}}(n-s)
\end{aligned}
$$

i.e., if $\gamma=n-s$ firms are better off not investing as they receive the spill with probability 1. On the other hand, if $\gamma=0$, we have that

$$
\begin{aligned}
\pi_{\mathcal{N} \backslash \mathcal{I}}(0) & =A(0)\left[\frac{s}{n-\beta^{*}(0)}\left(1+k^{*}(0)\right)^{\frac{\alpha \rho}{1-\alpha}}+\frac{n-\beta^{*}(0)-s}{n-\beta^{*}(0)}\right] \\
& <A(0)\left(1+k^{*}(0)\right)^{\frac{\alpha \rho}{1-\alpha}}-k^{*}(0) \\
& =\pi_{\mathcal{I}}(0)
\end{aligned}
$$

is satisfied for $s$ small enough. So, by continuity there exists $\gamma_{m i} \in[0, n-s]$ such that (4) is satisfied. From $\gamma_{m i}$, we can derive $\beta_{m i} \equiv \beta^{*}\left(\gamma_{m i}\right)$ and $k_{m i} \equiv k^{*}\left(\gamma_{m i}\right)$. Finally, one 
can determine the price charged by contractor $j$ to perform the task. Observe that the chosen contractor will extract $\beta_{m i} \phi\left(\left(1+k_{m i}\right)^{-\rho}, \beta_{m i}\right)$ as a surplus from the market for information. The initial competition among contractors guarantees that the price for the task is $\tau_{j}=-\frac{\beta_{m i} \phi\left(\left(1+k_{m i}\right)^{-\rho}, \beta_{m i}\right)}{n}$.

Third step (uniqueness): To show that the equilibrium described above is unique, let us first show that (1) there cannot be equilibria where some firms both invests and outsources and some others invest and do not outsource, (2) there cannot be equilibria where only a zero-measured set of firms invest, (3) there cannot be equilibria where a zeromeasured set of firms do not invest. Points (1), (2) and (3) guarantee that in equilibrium the firms are always divided into two exaustive and positive-measured sets, the investing and the not investing firms, and all the investing firms invest the same amount and they do outsource. Then, in (4), I will show that the measure $\gamma_{m i}$ that guarantees indifference between the two sets (as determined in the previous step) is uniquely identified.

(1) First of all, recall that if more than one firm invests and outsources, it must be the case they outsource from the same contractor. This implies that these firms invest exactly the same amount (as none of them is relevant to change the knowledge of the monopolistic contractor) of the not-outsourcing firms. Then, any of the not-outsourcing firms would have a profitable deviation in outsourcing. Suppose instead that there is exactly one firm, say firm $i$, that invest and outsources. In its optimal investment problem, firm $i$ will have to take into account the fact that the monopolistic contractor the firm hires anticipates to learn information from $i$, and to leak it on the market for information (in the timing of the game we presented, the price paid for the task is not responsive to the investment decision of this contractor because it is posted simultaneously to the investment decision. Then, the optimal investment level of firm $i$ is lower than the investment level of the others). Now, observe that in equilibrium the investing and not-outsourcing firms must have the same expected payoff as the non-investing firms. Firm $i$ cannot be worse off than these two sets of firm (if this were the case, it would have a profitable deviation in not outsourcing and investing more). Also, firm $i$ cannot be better off than these two sets of firms (if this were the case, any investing and not-outsourcing firm would have a profitable deviation in following the same strategy of firm $i$ ). Then, firm $i$ must get the same payoff 
as the two sets of firm. It is easy to verify that such indifference can occurr in equilibrium only for a zer-measured set of parameters of the model.

(2) Recall that for $s<\bar{s}$ we have $\pi_{\mathcal{I}}(0)>\pi_{\mathcal{N} \backslash \mathcal{I}}(0)$, so if a zero-measured set of firms invest in equilibrium, one of the other firms would have a profitable deviation in investing (notice that this is true even if the set of investing firm includes only one firm, so for small $s$ we can rule out an equilibrium in which only one firm invests and outsources). (3) Notice that if $s>0$, then $\pi_{\mathcal{N} \backslash \mathcal{I}}(n-s)>\pi_{\mathcal{I}}(n-s)$, as if a $(n-s)$-measured set of firms invest, a firm would have a profitable deviation in waiting for the spill.

(4) To guarantee that $\gamma$ is uniquely determined, it is enough to show that the functions $\pi_{\mathcal{N} \backslash \mathcal{I}}(\gamma)$ and $\pi_{\mathcal{I}}(\gamma)$ cannot cross twice. To see this, observe that, by the Envelope theorem, we have

$$
\frac{d \pi_{\mathcal{I}}(\gamma)}{d \gamma}=\frac{\partial A(\gamma)}{\partial \gamma} c^{*}(\gamma)^{-\frac{\alpha}{1-\alpha}}
$$

and

$$
\frac{d \pi_{\mathcal{N} \backslash \mathcal{I}}(\gamma)}{d \gamma}=\frac{\partial A(\gamma)}{\partial \gamma} K(\gamma)+A(\gamma) \frac{\partial K(\gamma)}{\partial \gamma}
$$

where $K(\gamma) \equiv 1+\frac{s}{n-\gamma-\beta^{*}(\gamma)}\left(c^{*}(\gamma)^{-\frac{\alpha}{1-\alpha}}-1\right)$. Notice that $\frac{\partial A(\gamma)}{\partial \gamma}=\frac{\partial A(\gamma)}{\partial\left(\gamma+\beta^{*}(\gamma)\right)} \frac{\partial\left(\gamma+\beta^{*}(\gamma)\right)}{\partial \gamma}$ and $\frac{\partial K(\gamma)}{\partial \gamma}=\frac{\partial K\left(\gamma+\beta^{*}(\gamma)\right)}{\partial\left(\gamma+\beta^{*}(\gamma)\right)} \frac{\partial\left(\gamma+\beta^{*}(\gamma)\right)}{\partial \gamma}$. After some algebraic manipulations, one can see that $\frac{\partial A(\gamma)}{\partial\left(\gamma+\beta^{*}(\gamma)\right)}<0$ and $\frac{\partial K\left(\gamma+\beta^{*}(\gamma)\right)}{\partial\left(\gamma+\beta^{*}(\gamma)\right)}>0$. Moreover, notice that it must be the case that $\frac{\partial\left(\gamma+\beta^{*}(\gamma)\right)}{\partial \gamma}>0$ for all $\gamma$ (to see this, suppose $\frac{\partial\left(\gamma+\beta^{*}(\gamma)\right)}{\partial \gamma}<0$ for some interval of $\gamma$, and notice that in that interval it should be the case that $\frac{k(\gamma)}{\partial \gamma}>0$, which, together with $\frac{\partial\left(\gamma+\beta^{*}(\gamma)\right)}{\partial \gamma}<0$, would imply that for a positive change of $\gamma$ the function $\varphi(\beta)=\frac{W(1-\alpha)\left[c^{\frac{-\alpha}{1-\alpha}}-1\right]}{(\gamma+\beta)\left[\underline{c}^{\frac{-\alpha}{1-\alpha}}-1\right]+n}$ shifts upward, which would imply $\beta^{*}$ to increase, which is in contradiction with $\left.\frac{\partial\left(\gamma+\beta^{*}(\gamma)\right)}{\partial \gamma}<0\right)$. All these considerations imply that $\frac{d \pi_{\mathcal{I}}(\gamma)}{d \gamma}<0$ and that for all $\gamma \in[0 . n]$ we have 


$$
\begin{aligned}
\frac{d \pi_{\mathcal{N} \backslash \mathcal{I}}(\gamma)}{d \gamma} & >\frac{\partial A(\gamma)}{\partial\left(\gamma+\beta^{*}(\gamma)\right)} \frac{\partial\left(\gamma+\beta^{*}(\gamma)\right)}{\partial \gamma} K\left(\gamma+\beta^{*}(\gamma)\right) \\
& >\frac{\partial A(\gamma)}{\partial\left(\gamma+\beta^{*}(\gamma)\right)} \frac{\partial\left(\gamma+\beta^{*}(\gamma)\right)}{\partial \gamma} c^{*}(\gamma)^{-\frac{\alpha}{1-\alpha}} \\
& =\frac{d \pi_{\mathcal{I}}(\gamma)}{d \gamma}
\end{aligned}
$$

which guarantees that $\pi_{\mathcal{N} \backslash \mathcal{I}}(\gamma)$ and $\pi_{\mathcal{I}}(\gamma)$ cannot cross twice

\section{References}

[1] Abraham K.G. and S.K. Taylor (1996) "Firm's Use of Outside Contractors: Theory and Evidence," Journal of Labor Economics, 14

[2] Anton J. and D. Yao (2002a), "The Sale of Ideas: Disclosure, Property Rights and Incomplete Contracts", Review of Economic Studies, 69 vol.3.

[3] Anton J. and D. Yao (2002b), "Attracting Skeptical Buyers", Working Paper

[4] Azoulay P. (2004) "Capturing Knowledge Across and Within Firm Boundaries: Evidence from Clinical Development." American Economic Review, 94(5), pp. $1591-1612$

[5] Baccara M. and H. Bar-Isaac (2005), "How to Organize Crime", Mimeo

[6] Baccara M. and R. Razin (2002), "From Thought to Practice: Appropriation and Endogenous Market Structure with Imperfect Intellectual Property Rights", Mimeo, New York University

[7] Bartel A., S. Lach and N. Sicherman (2005), "Outsourcing and Technological Change," Mimeo

[8] Benveniste L.M., A.P. Ljungqvist, W.J.Wilhelm, X. Yu (2003) "Evidence of Information Spillovers in the Production of Investment Banking Services", forthcoming on Journal of Finance 
[9] Bernheim B.D. and M.D. Whinston (1985), "Common marketing agency as a device for facilitating collusion", Rand Journal of Economics, 16(2)

[10] Bernheim B.D. and M.D. Whinston (1986), "Common Agency", Econometrica, $54(4)$

[11] Bhide A.V. (1996), "Building the Professional Firm: McKinsey \& Co.: 19391968", Working Paper

[12] Ceccagnoli M. (2000), "The Effect of Spillovers and Rivalry among Firms with Heterogeneous Technological Capabilities on R\&D Efforts", Working Paper

[13] Coase R. (1937), "The Nature of the Firm”, Economica, 4

[14] Demski J.S., T.R. Lewis, D. Yao and H. Yildirim (1999), "Practices for Managing Information Flows within Organizations", Journal of Law, Economics and Organizations, 15(1)

[15] DiMaggio P.J and W.W. Powell (1983), "The Iron Cage Revisited: Institutional Isomorphism and Collective Rationality in Organizational Fields," American Sociological Review 48

[16] Estevao M., S.Lach (1999), "The Evolution of the Demand for Temporary Help Supply Employment in the United States", NBER Working Paper

[17] Feenstra R.C. (1998), "Integration of Trade and Disintegration of Production in the Glogal Economy", Journal of Economic Prespectives, 12

[18] Grossman S.J. and O.Hart (1986) "The Costs and Benefits of Ownership: a Theory of Vertical and Lateral Integration", Journal of Political Economy, 94

[19] Grossman G. and E. Helpman (2002a), "Integration vs. Outsourcing in Industry Equilibrium", Quarterly Journal of Economics, vol.117(1)

[20] Grossman G. and E. Helpman (2002b), "Outsourcing in a Global Economy", NBER Working Paper 8728 
[21] Hart O. and J.Moore (1990), "Property Rights and the Nature of the Firm", Journal of Political Economics, 98(6), 1119-1158

[22] Helper S. (1991), "Strategy and Irreveribility in Supplier Relations: The Case of the U.S. Automobile Industry", Business History Review, 65

[23] Holmstorm B. and J. Roberts (1998), "The Boundaries of the Firm Revisited", Journal of Economic Perspectives, vol. 12(4)

[24] Jansen J. (2005), "Information Acquisition and Strategic Disclosure in Oligopoly", Mimeo

[25] Jovanovic B. and G.M. MacDonald (1994), "Competitive Diffusion", Journal of Political Economy, vol.102(1)

[26] Kipping M. and T. Armbruster (2004), "Management Consultants and Management Knowledge: a Literature Review", University of Reading, Mimeo.

[27] Klein B., R.Crawford and A.Alchian (1978), "Vertical Integration, Appropriable Rents, and the Competitive Contracting Process", Journal of Law and Economics, 21(2), 297-326

[28] Levin R.C., A.K. Klevorick, R.R. Nelson and S.G. Winter (1987), "Appropriating the Returns from Industrial Research and Development", Brookings Papers on Economic Activity, 3

[29] Lewis T.R. and D.A. Yao (2001) "Innovation, Knowledge Flow, and Worker Mobility", Working Paper, Wharton School of Business.

[30] Mayer K.J. (2000), "The Stretegic Utilization of Subcontractors in High Technology Industries: Evidence from Information Technology", Mimeo, Marshall School of Business, University of Southern California

[31] McKenna C.D. (2001), "The World's Newest Profession: Management Consulting in the Twentieth Century", Enterprise and Society, 2 (Dec 2001) 
[32] Rajan R.G. and L. Zingales (2001), "The Firm as a Dedicated Hierarchy: A Theory of the Origin and Growth of Firms", Quarterly Journal of Economics

[33] Tempest R. (1996), "Barbie and the World Economy", The Los Angeles Times, Sep 22, 1996

[34] Williamson O. (1985), "The Economic Institution of Capitalism", New York: Free Press

[35] World Trade Organization (1998), "Annual report 1998" Geneva: World Trade Organization

[36] Zabojnik J. (2002), "A Theory of Trade Secrets in Firms", International Economic Review 43 